\title{
Microbial Transformation of Clarias gariepinus Oil by Psuedomonas aeruginosa
}

\author{
MUHAMMAD NOR OMAR, NORHAYATI SHABAN, \\ LATIFAH MUNIRAH BAKAR and AHMAD MUZAMMIL ZUBERDI
}

Department of Biotechnology, Kulliyyah of Science, International Islamic University Malaysia, Kuantan, 25200, Pahang Malaysia.

http://dx.doi.org/10.13005/ojc/300327

(Received: July 30, 2014; Accepted: August 31, 2014)

\begin{abstract}
Biotransformation of fatty acid from Malaysian catfish, Clarias gariepinus oil was carried out using Pseudomonas aeruginosa. The lipid from freeze-dried catfish flesh was extracted using a modified Folch method with chloroform-methanol mixture as an extracting solvent. The crude lipid substrate was added to $P$. aeruginosa culture and incubated for 4 days. After conversion, the products were analyzed by using GC-MS instrument. The result showed that 7,10-dihydroxy-8(E)octadecenoic acid (DHOD) were abundantly found in the product. The hydroxyl derivative increased while fatty acid contents decreased after biotransformation process. It can be concluded that the bacterial cells had transformed the fatty acids to yield hydroxyl metabolite which can be utilized as starting materials for the bioconversion to pharmaceutical materials.
\end{abstract}

Key words: Biotransformation, Clarias gariepinus oil, Pseudomonas aeruginosa.

\section{INTRODUCTION}

Biotransformation can be defined as an application that utilizes natural and recombinant organisms' enzymes secreted by yeast, fungi and bacteria or whole cells as biocatalyst in converting the organic compound into important metabolites. Many studies on the bioconversion of $\omega$-fatty acids have been carried out recently. Hosokawa et. al. ${ }^{1}$ obtained at least eight biotransformation products from ù-3 and ù-6 polyunsaturated fatty acids through biotransformation using Clavibacter sp. ALA2 as catalyst. The bacterium has converted arachidonic acid (ù-3) into epoxy and hydroxy fatty acids including 14,19;15,19-diepoxy-, 14-hydroxy-15,18epoxy-and 12,15,19-trihydroxy-5,8,11-eicosatrienoic acid (Figure 1) whereas 12,17;13,17-diepoxy-, 12-hydroxy-13,16-epoxy- and 12,13,17-trihydroxy6,9-octadecadienoic acid were obtained from $\gamma$-linolenic acid $(\omega-6)$. 
The study by Kishimoto et. $\mathrm{al}^{2}$ found that lactic acid bacteria transformed linoleic acid into hydroxy FA. For example, Lactobacillus acidophilus and Pediococcus pentosaceus produced 13(S)-hydroxy-9octadecenoic acid and 10,13-dihydroxyoctadecanoic acid from linoleic acid. Besides Clavibacter and Lactobacillus strains, Kim et. al. ${ }^{3}$ utilised P.seudomonas aeruginosa bacterium to produce $7,10,12$ - trihydroxy$8(E)$-octadecenoic acid from ricinoleic acid. The new compound was formed by two additional hydroxyl groups at carbon 7 and 10 and rearrangement of the double bond from carbon 9-10 (cis) to 8-9 (trans) as shown in the figure 2. A review on the utilization of $P$. aeruginosa for converting fatty acids has been compiled by Kuo et $\mathrm{al}^{4}$. Based on this revision, Chang et al ${ }^{5}$ have transformed triolein into 7,10-dihydroxy8(E)-octadecenoic acid using $P$. aeruginosa PR3 while Suh et $a^{6}$ produced the similar dihydroxy acid from olive oil using the same bacteria. Meanwhile, Kuo et $\mathrm{al}^{7}$ obtained 10-hydroxy-8(E)- octadecenoic acid when incubating oleic acid with $P$. aeruginosa. Since the studies on biotransformation of animal fats, including fish oil, are very limited, this work is initiated with the main aim to investigate the possibility of converting fish oil, in particular fatty acids, into a variety of metabolites.

\section{EXPERIMENTAL}

\section{Extraction of fish oil}

The catfish was obtained from Koperasi Shamelin Catfish Farm, Janda Baik, Pahang, Malaysia in October 2013. The fish was cooled with ice, transported to Food Bioprocess Laboratory Kulliyyah of Science, beheaded and cut into small pieces.

\section{Crude Lipid Extraction from Catfish}

After grinding ca. $790 \mathrm{~g}$ of catfish flesh was dried using a freeze dryer (model Alpha 1-4, Christ $\mathrm{GmbH}$, Osterode, Germany). Approx. $75 \mathrm{~g}$ of dried sample was used for lipid extraction by a modified Folch method using chloroform and methanol solvents $(2: 1)$ system $^{8,9}$. After 5 days of shaking the solvent layer was filtered and concentrated using a rotary evaporator (BUCHI rotavapor R- 210, Switzerland).

Pseudomonas aeruginosa bacterial culture preparation and biotransformation

$P$. aeruginosa pure bacterial culture was streaked on nutrient agar (NA) plate and incubated for $24 \mathrm{~h}$ at $37^{\circ} \mathrm{C}$. The bacterial cells were then inoculated in a conical flasks containing NA broth. After $24 \mathrm{~h}$ inoculation, $20 \mu \mathrm{l}$ of bacterial culture was taken from the bacterial stock culture and inoculated at $28^{\circ} \mathrm{C}$ for $24 \mathrm{~h}$ in a new conical flask containing NA broth. Then, $1 \mathrm{~g}$ of crude $C$. gariepinus lipid was added and incubated for $4 \mathrm{~d}$ at $28^{\circ} \mathrm{C}$.

\section{Biotransformation Product Recovery}

After incubation, $6 \mathrm{~N}$ hydrochloric acid $(\mathrm{HCl})$ was added to the mixture until the $\mathrm{pH}$ 2. Then, the acidified mixture was centrifuged and supernatant was extracted using ethyl acetate followed by diethyl ether. The combined solvent layer was concentrated using $\mathrm{BUCHI}$ rotavapor R-210. The biotransformation product was methylated using method previously reported $^{8,9}$.

\section{GC-MS analysis}

The methylated fatty acids from the fish lipid and biotransformation product were identified by using Perkin Elmer Auto System XL Gas Chromatograph and Perkin Elmer Turbo Mass Gold Mass Spectrometer (GC-MS system). During the GC-MS analysis, helium gas was used as carrier gas at flow rate of $1 \mathrm{ml} / \mathrm{min}$. The initial temperature was set to $50^{\circ} \mathrm{C}$ for 2 minutes and the temperature was programmed with heating ramp of $5^{\circ} \mathrm{C} / \mathrm{min}$ until it reached the final temperature of $250^{\circ} \mathrm{C}$. The oven temperature was finally kept at $250^{\circ} \mathrm{C}$ for 10 minutes. The MS spectrum obtained from the GC-MS analysis was analyzed to identify fatty acids that present in the fish lipid and biotransformation product.

Figure 3 and 4 show the GC profiles of the fatty acids of $C$. gariepinus before and after biotransformation by $P$. aeruginosa. The fatty acid compositions and GC-MS analysis of the fish are shown in Table 1 and 2 . The most abundant fatty acid found in the crude lipid extract was oleic acid (C18:1, 43\%) followed by palmitic acid (C16:0, $28 \%$ ). Arachidonic acid and cholesterol contents were 1.4 and $4.8 \%$ respectively. Other fatty acids were capric acid (C10:0, 3.2\%), lauric acid (C12:0, $0.3 \%)$, myristic acid $(\mathrm{C} 14: 0,2.9 \%)$, palmitoleic acid (C16:1, 7.4\%) and stearic acid (C18:0, 4.8\%). Meanwhile, it was found that 7,10-dihydroxy-8(E)octadecenoic acid (89.5\%) (DHOD) was the most abundant compound found in lipid fraction after biotransformation process. The hydroxyl-fatty acid 
Table 1: GC analyses of crude lipid extracted from Clarias gariepinus

\begin{tabular}{lccc}
\hline Peak & Compound & $\mathbf{R}_{\mathbf{t}}(\mathbf{m i n})$ & Percentage (\%) \\
\hline 1 & C10:0 & 22.66 & 3.20 \\
2 & C12:0 & 26.93 & 0.31 \\
3 & C14:0 & 27.25 & 2.90 \\
4 & C16:1 & 31.01 & 7.41 \\
5 & C16:0 & 31.55 & 28.21 \\
6 & C18:1 & 34.96 & 42.93 \\
7 & C18:0 & 35.33 & 8.76 \\
8 & C22:4 & 37.53 & 1.38 \\
9 & Cholesterol & 44.82 & 4.78 \\
\hline
\end{tabular}

Table 2: Fatty acids from the catfish oil after biotransformation by $P$. aeruginosa

\begin{tabular}{lccc}
\hline Peak & Compound & $\mathbf{R}_{\mathbf{t}}(\mathbf{m i n})$ & Percentage (\%) \\
\hline 1 & C12:0 & 22.63 & 0.54 \\
2 & C16:0 & 31.39 & 2.55 \\
3 & C18:1 & 34.72 & 1.70 \\
4 & C18:0 & 35.24 & 0.27 \\
5 & DHOD & 44.61 & 89.47 \\
\hline
\end{tabular}

was similar with the product obtained by Chang et. al. ${ }^{6}$ when converting triolein using $P$. aeruginosa. Other compounds found were lauric acid (C12:0, $0.5 \%$ ), palmitic acid (C16:0, 2.6\%), oleic acid (C18:1, $1.7 \%)$ and stearic acid (C18:0, 0.3\%). The results also show that the percentages of the compounds found in both chromatographic results (before and after bioconversion) were different. For example, the percentage of palmitic acid (C16:0) decreased from $28.2 \%$ to $2.6 \%$ and oleic acid (C18:1) also decreased from $42.9 \%$ to $1.7 \%$ after biotransformation. Thus, it showed that some of the fatty acid compounds have been converted into other compounds by the bacteria during the biotransformation step, especially oleic acid (C18:1). As, for the high percentage of hydroxylfatty acid, it indicated that the fatty acids might be

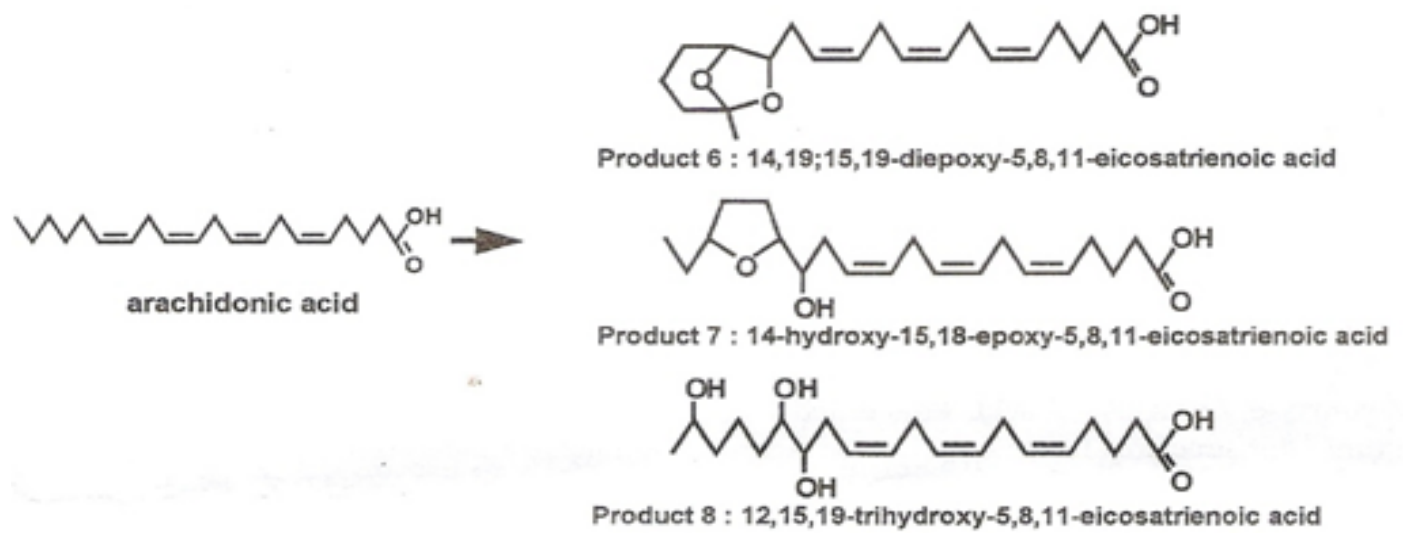

Fig. 1: Biotransformation products from arachidonic acid by Clavibacter sp. ALA2 ${ }^{1}$ 


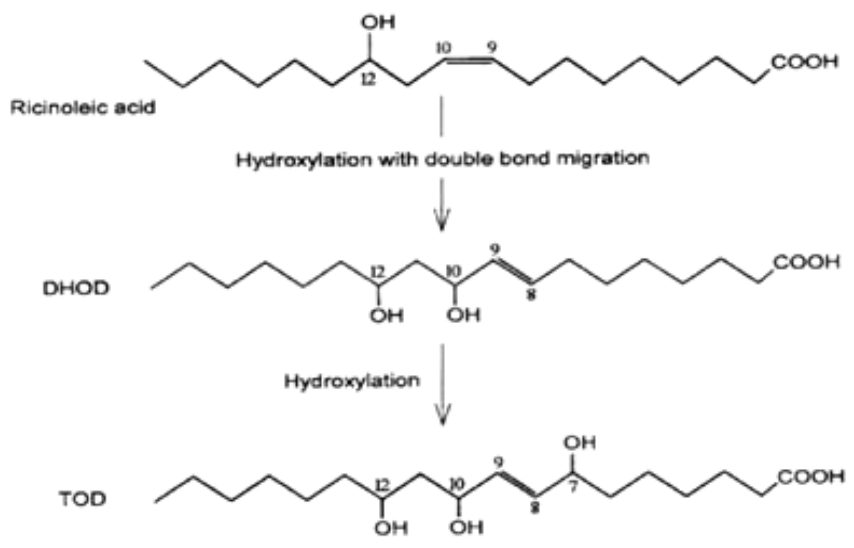

Fig. 2: Postulated bioconversion pathway of ricinoleic acid ${ }^{3}$

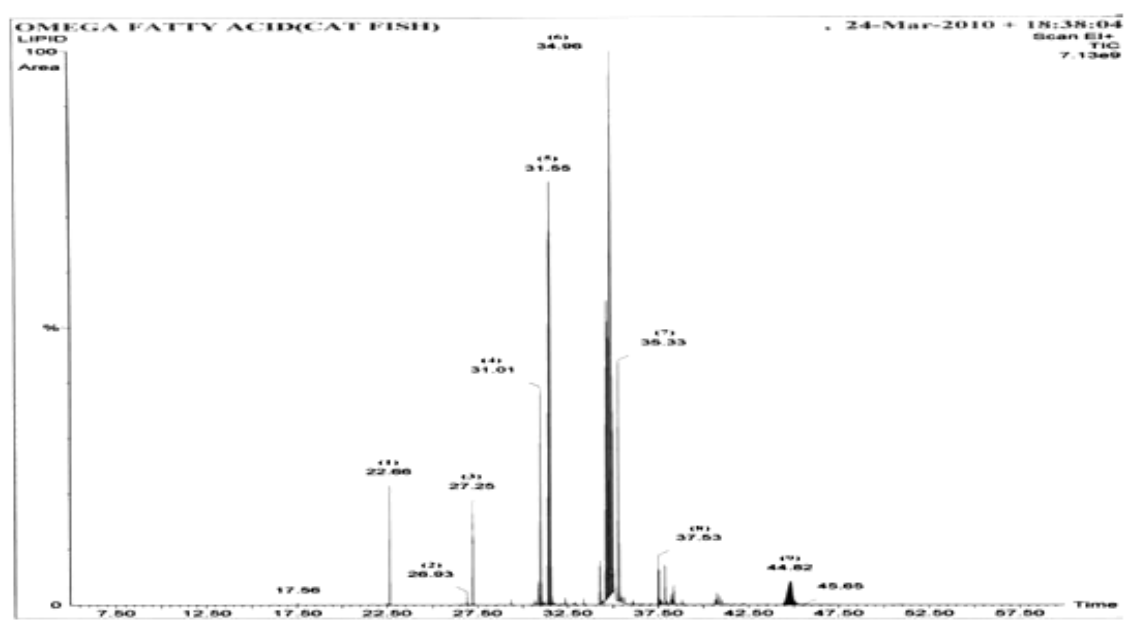

Fig. 3: GC chromatogram of crude lipid extracted from Malaysian catfish, Clarias gariepinus

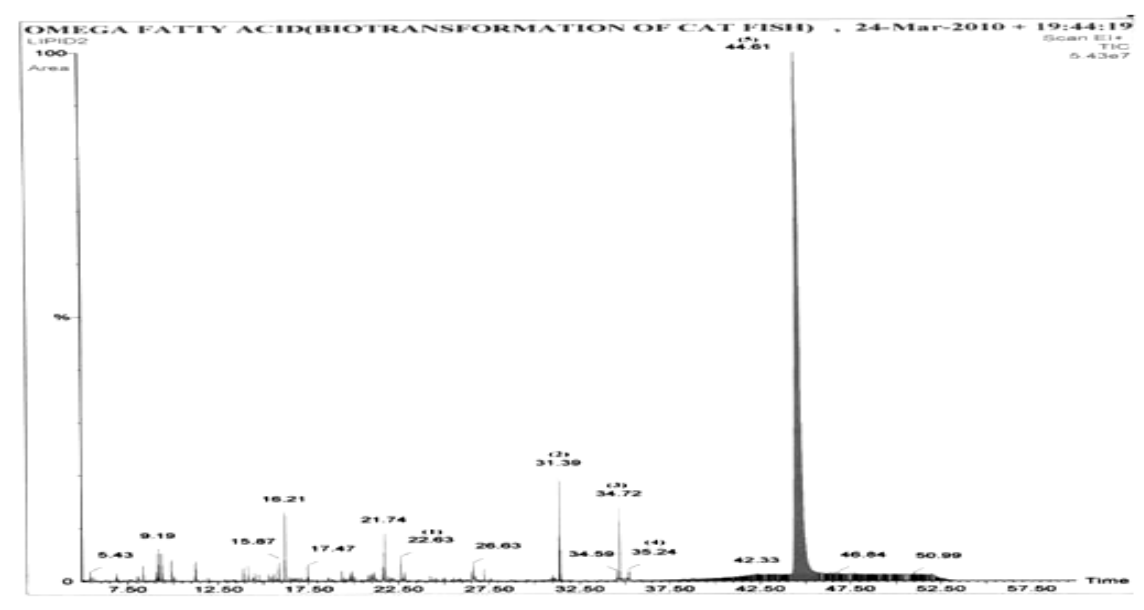

Fig. 4: GC chromatogram of Crude Lipid after Biotransformation by Pseudomonas aeruginosa bacterium 
converted into 7,10-dihydroxy-8(E)-octadecenoic acid (DHOD) by the bacteria. The biosynthetic mechanism of the formation of dihydroxy acid was not pastulated. However, Snider et al ${ }^{10}$ mentioned that, this compound was derived from acetyl Co-A which can be obtained from oxidation of fatty acids. Thus, the reduction in percentage amount of fatty acids after biotransformation step was due to the oxidation of fatty acids via acetyl Co-A formation which consequently was the starting material for dihydroxy-fatty acid synthesis.

\section{ACKNOWLEDGEMENTS}

The authors wish to thank the International Islamic University of Malaysia (IIUM) and the Ministry of Higher Education (MOHE) for financial support (FRGS). Also thanks to all Kulliyyah of Science (KOS) and IIUM staff for technical support.

\section{REFERENCES}

1. Hosokawa, M.; Hou, C.T.; Weisleder, D. JOACS. 2003, 80, 1085-1091 http://www. springerlink.com/content/07644tv562517622/ fulltext.pdf

2. Kishimoto, N.; Yamamoto, I.; Toraishi, K.; Yoshioka., S.; Saito, K.; Masuda, H.; Fujita, T. (2003). Lipids 2003, 38, 12691274 doi: 10.1007/s11745-003-1188-4; http://dx.doi. org/10.1007/s11745-003-1188-4

3. Kim, H.; Kuo, T. M.; Hou, C. T. Journal of Industrial Microbiology \& Biotechnology 2000, 24, 167-172 http://www. springerlink. com/content/wb 1 lcuv8rkh37 th3/fulltext.pdf

4. Kuo, T. M.; Manthey, L. K.; Hou, C.T. JAOCS. 1998, 75, 875-879 http://www.springerlink. com/content/k55r40856634340p/fulltext.pdf

5. Chang, I. A.; Kim, I. H.; Kang, S. C.; Hou, C. T.; Kim, H. R. Appl. Microbiol. Biotechnol. 2007, 74, 301-306 doi:10.1007/s00253-0060662-5, http://dx.doi.org/10.1007/s00253006-0662-5

6. Suh, M. J.; Baek, K. Y.; Kim, B. S.; Hou, C. T.; Kim, H. R. Appl Microbiol. Biotechnol. 2011,
89, 1721-1727 doi: 10.1007/s00253-0103040-2, http://dx.doi.org/ 10.1007/s00253010-3040-2

7. Kuo, T. M.; Huang, J. K.; Labeda, D.; Wen, L.; Knothe, G. Curr. Microbiol. 2008, 57, 437 -44 doi: 10.1007/s00284-008-9226-5; http:// dx.doi.org/10.1007/s00284-008-9226-5

8. Omar, M. N.; Yusoff, N. S. A. M.; Zainuddin, N. A.; Yunus, K. Oriental Journal of Chemistry 2010, 26, 1-4 http://www.orientjchem.org/ archiveabs. php?vol=026\&issue=01\&pg=0.

9. Omar, M. N.; Siti Fairuz, C. O.; Hasan, M. T.; Nor. Nazuha, M. N.; Nor Dalilah, M. N.; Kamaruzzaman, Y. Oriental Journal of Chemistry 2010, 26, 861864 http://orientjchem.org/dnload/MNOMAR-CO-SITIFAIRUZ-MT-HASANOAMN-NORNAZUHA-MN-NORDALILAH/ OJCV026I03P861-864.pdf

10. Snider, M. D.; McGarry, J. D.; Hanson, R. W. In Devlin, T.M. (Ed.). Textbook of Biochemistry with Clinical Correlations (pp. 661-741). Wiley, United States of America (2006) 